\title{
Evaluasi Motor Listrik Sebagai Penggerak Mobil Listrik
}

\section{Evaluation of Electric Motor as The Main Actuator of Electric Vehicle}

\author{
Angga Wahyu Aditya ${ }^{1 *}$, Ihsan ${ }^{2}$, Restu Mukti Utomo ${ }^{3}$, Hilmansyah ${ }^{4}$ \\ 1,2,3,4 Politeknik Negeri Balikpapan \\ Jl. Soekarno Hatta KM. 8 , Balikpapan 76129, Indonesia. \\ 1,2,3,4) Program Studi Teknik Elektro, Jurusan Teknik Elektro \\ Politeknik Negeri Balikpapan \\ email: ${ }^{* 1}$ angga.wahyu@poltekba.ac.id, ${ }^{2}$ ihsan@poltekba.ac.id, ${ }^{3}$ restu.mukti@poltekba.ac.id, \\ 4hilmansyah@poltekba.ac.id
}

DOI:

$10.30595 /$ jrst.v3i2.4142

Histori Artikel:

Diajukan:

$07 / 05 / 2019$

Direvisi:

$15 / 07 / 2019$

Diterima:

$20 / 07 / 2019$

\section{ABSTRAK}

Pengembangan konsep kendaraan Low-Cost Green Car (LCGC) dan zero emission menjadi fokus penelitian pada beberapa negara. Hal ini dilatarbelakangi cadangan bahan bakar minyak yang terus menurun dan bahaya pencemaran lingkungan. Motor listrik merupakan satu satunya penggerak utama yang dapat diaplikasikan pada mobil listrik yang mengusung kedua konsep tersebut. Pada generasi awal pengembangan mobil listrik, motor DC menjadi solusi yang paling sesuai dikarenakan kemudahan pengoperasiannya dan pengaturan kecepatannya. Setelah teknologi kontrol vektor untuk motor induksi ditemukan dan dikembangkan, motor induksi mulai dipakai oleh beberapa pabrikan mobil listrik. Pada kontrol vektor, fluks dan torsi pada motor induksi dapat dikendalikan secara terpisah sehingga pengaturan motor induksi menyerupai motor DC. PMSM merupakan satu - satunya jenis motor listrik yang mampu menyamai motor induksi sebagai penggerak mobil listrik. Namun, PMSM memiliki kekurangan yang sangat vital yaitu mudah mengalami kerusakan magnetisasi akibat panas atau reaksi armature, sehingga diperlukan penelitian lebih lanjut untuk mengaplikasikan PMSM pada mobi listrik. Motor listrik jenis SRM banyak digunakan pada mobil hybrid yang memadukan penggunaan mesin berbahan bakar minyak dengan motor listrik. SRM memiliki banyak kekurangan apabila diaplikasikan pada mobil listrik berskala kecil namun sangat sesuai untuk diaplikasikan pada mobil listrik berskala besar seperti bis.

Kata Kunci: Motor listrik, motor induksi, mobil listrik, emisi nol.

\begin{abstract}
The development of the Low-Cost Green Car (LCGC) and zero emission vehicle concepts is the focus of research in several countries. This is motivated by declining oil fuel reserves and the danger of environmental pollution. Electric motors are the only prime movers that can be applied to electric cars that carry these two concepts. In the early generation of electric car development, DC motors were the most suitable solution due to their ease of operation and speed regulation. After vector control technology for induction motors was discovered and developed, induction motors began to be used by several electric car manufacturers. In vector control, the flux and torque in the induction motor can be controlled separately so that the arrangement of the induction motor resembles a DC motor. PMSM is the only type of electric motor that is able to match an induction motor as an electric car driver. However, PMSM has a very vital disadvantage that is easily damaged by magnetization due to heat or armature reaction, so further research is needed to apply PMSM to the electric vehicle. SRM electric motors are widely used in hybrid cars that combine the use of oil-fueled engines with electric motors.
\end{abstract}


SRM has many disadvantages when applied to small-scale electric cars but is very suitable to be applied to large-scale electric cars such as buses.

Keywords: electric motor, induction motor, electric car, zero emission.

\section{PENDAHULUAN}

Mobil listrik dewasa ini menjadi fokus riset tersendiri dalam pengembangan teknologi transportasi (Fard, Khajepour, Goodarzi, \& Esmailzadeh, 2012), (Yaich, Hachicha, \& Ghariani, 2015), (Saleki, Rezazade, \& Changizian, 2017), (Sriwilai, Pattaraprakorn, Chutiprapat, Sansilah, \& Bhasaputra, 2016). Konsep LCGC dan zero emission yang di tawarkan menjadi alasan utama pengembangan teknologi mobil listrik untuk menjawab kelangkaan bahan bakar minyak dan bahaya pencemaran lingkungan (Eisler, 2016), (BPPT, 2018). Pengembangan motor listrik seperti Permanent Magnet Synchronous Motor (PMSM), Switched Reluctanced Motor (SRM), motor induksi dan Brushless DC Motor (Hashernnia \& Asaei, 2008), (Yang, Shang, Brown, \& Krishnamurthy, 2015), (Jaya, et al., 2017), (Assegaf, Purwadi, Rachmilda, \& Haroen, 2013) sebagai penggerak utama yang sesuai untuk mobil listrik menjadi fokus riset tersendiri.

Penggunaan motor listrik untuk mobil listrik telah banyak diteliti. Motor listrik jenis motor DC (termasuk motor brushless DC) digunakan pada mobil listrik dengan daya rendah (Hashernnia \& Asaei, 2008). Jenis motor ini digunakan oleh produsen otomotive Peugeot yang berasal dari Perancis untuk Hybrid Electric Vehicle (HEV) yang diberi nama "Dynavolt". Motor Induksi merupakan jenis motor listrik yang sesuai untuk mobil listrik dikarenakan tingkat kesiapan teknologi yang tinggi, kehandalan dan hampir tidak memerlukan perawatan. PMSM merupakan saingan utama dari motor induksi. Hal ini dikarenakan power density dan efisiensi yang tinggi serta lebih efektf dalam pendistribusian panas. Produsen mobil lisrik yang menggunakan PMSM diantaranya Toyota, Honda dan Nissan. Motor listrik jenis SRM banyak digunakan pada kendaraan hibrid. Beberapa keuntungan dari SRM adalah : desain yang simpel, konstruksi motor yang kokoh, toleransi kesalahan, sistem kendali yang sederhana dan memiliki karakteristik torsi kecepatan yang baik. Namun, SRM memiliki beberapa kerugian antara lain : noise yang dan ripple torsi yang tinggi dan topologi konverter yang khusus.

Publikasi ilmiah ini membahas mengenai jenis motor listrik yang dapat diaplikasikan sebagai penggerak mobil listrik. Penerapan motor induksi pada mobil listrik menjadi fokus utama bahasan publikasi ilmiah ini. Motor induksi dipilih dikarenakan keunggulan dan harga yang lebih murah dari jenis motor listrik lainnya. Selain itu perkembangan teknologi pengemudi kontrol vektor pada motor induksi membuat pengaturan motor induksi seperti motor DC. Hal inilah yang mendorong produsen mobil listrik Tesla beralih ke motor induksi sebagai penggerak utamanya.

\section{METODE PENELITIAN}

\subsection{Studi Literatur}

Pengumpulan data - data

dilakukan dengan mengevaluasi publikasi ilmiah (seminar, prosiding dan jurnal) baik pada skala nasional maupun internasional dengan batasan 15 tahun terakhir untuk mendapatkan data yang akurat dan terbaru.

\subsection{Penggerak Mobil Listrik}

Motor DC

Motor DC merupakan motor yang paling mudah digunakan pada mobil listrik pada masa lalu. Hal ini dikarenakan kemudahan pada pengaturan dan memiliki fluks dan torsi yang terpisah. Namun, motor DC memiliki kerugian di sisi perawatan. Oleh karena itu, setelah perkembangan teknologi kendali vektor untuk motor AC (motor induksi) penggunaan motor DC untuk mobil listrik mengalami penurunan.

\section{Motor Induksi}

Motor induksi merupakan jenis motor listrik yang paling sesuai untuk mobil listrik. Motor induksi sangkar tupai merupakan jenis motor yang memungkinkan diaplikasikan pada mobil listrik. Hal ini dikarenakan kehandalan, ketahanan terhadap gangguan, tidak memerlukan perawatan yang intens dan kemampuan untuk bekerja pada lingkungan yang ekstrim (Hashernnia \& Asaei, 2008), (Mehazzem, Nemmour, \& Reama, 2017).

Keunggulan motor induksi dibandingkan motor DC antara lain : motor induksi hampir tidak memerlukan perawatan, harga motor induksi lebih murah daripada 
motor DC pada daya nominal yang sama, berat motor induksi lebih ringan dari motor DC, motor induksi lebih kokoh dari motor DC dan bekerja lebih baik pada kondisi lingkungan yang ekstrim, motor induksi dapat didesain untuk daya yang lebih tinggi dengan tegangan nominal sampai $25 \mathrm{KV}$ serta kecepatan putar mencapai $50.000 \mathrm{rpm}$ (Bitar \& Jabi, 2014). Dewasa ini produsen mobil listrik Tesla menggunakan motor induksi sebagai penggerak utama Tesla Model $S$ yang merupakan varian mobil listrik terbaik dan termahal (Sieklucki, 2018).

\section{PMSM}

PMSM merupakan satu - satunya motor listrik yang mampu menyamai motor induksi sebagai penggerak mobil listrik. PMSM memiliki beberapa keunggulan, diantaranya: berat keseluruhan dan ukuran PMSM lebih kecil sehingga memiliki power density yang tinggi, efisiensi yang lebih baik daripada motor induksi dan distribusi panas yang lebih baik daripada motor induksi. Kerugian dari PMSM adalah mudah mengalami kerusakan magnetisasi akibat panas atau reaksi armature.

\section{SRM}

Riset mengenai Hybrid Electric Vehicle (HEV) banyak menggunakan SRM sebagai penggerak utama. Hal ini dikarenakan konstruksi yang sederhana dan kokoh, toleransi kesalahan saat pengoperasian, metode kontrol yang sederhana dan karakteristik kecepatan - torsi yang baik. Bagaimanapun juga, SRM memiliki banyak kelemahan diantaranya : produksi acoustic dan electromagnetic-interference (EMI) noise, riple torsi, topologi konverter yang khusus dan riak arus bus yang berlebihan (Kiyota, Kakishima, Sugimoto, \& Chiba, 2013), (Kumar \& D.Susitra, 2016), (Zeraoulia, Benbouzid, \& Diallo, 2006). Namun, SRM merupakan solusi yang sesuai untuk untuk penggunaan mobil hybrid sekala besar (Wang, Zhan, Ma, \& Zhou, 2005).

\section{HASIL DAN PEMBAHASAN}

Penggunaan motor listrik pada dunia otomotive telah diaplikasikan pada beberapa tipe mobil hybrid maupun mobil listrik oleh sejumlah produsen seperti Toyota, Honda, BMW, Nissan, Peugeot dan Tesla seperti yang ditunjukkan pada Tabel 1. Motor DC digunakan produsen otomotive asal Perancis yaitu PSA Peugeot untuk mobil listrik merk Berlingo. Motor SRM digunakan oleh produsen asal Australia (Holden) untuk merk ECOmmdore. Produsen mobil listrik asal Jepang mayoritas menggunakan PMSM sebagai penggerak utama. Beberapa mobil listrik asal Jepang yang menggunakan PMSM adalah Nissan - Tino, Toyota - Prius dan Honda - Insight. Motor induksi digunakan oleh produsen mobil listrik asal Eropa dan Amerika seperti Renault Kangoo asal Perancis, Chevrolet - Silverado asal USA, BMW - X5 asal Jerman dan yang terbaru adalah Tesla - Model S asal Sinted States of America (USA) seperti yang ditunjukkan oleh Gambar 1. Pengguanaan motor induksi pada beberapa pabrikan dilatarbekangi pengembangan teknologi kontrol vektor. Pada kontrol vektor, fluks dan torsi pada motor induksi dapat dikontrol secara terpisah seperti pada motor DC.

Tabel 1. Penggunaan Motor Listrik pada Industri Otomotif

\begin{tabular}{ccc}
\hline Model & Negara & $\begin{array}{c}\text { Jenis Motor } \\
\text { Listrik }\end{array}$ \\
\hline $\begin{array}{c}\text { PSA Peugeot- } \\
\text { Citroen / }\end{array}$ & Perancis & Motor DC \\
Berlingo & & \\
Holden / & Australia & SRM \\
ECOmmodore & Jepang & PMSM \\
Nissan / Tino & Jepang & PMSM \\
Honda / & Jepang & PMSM \\
Insight & Motor \\
Toyota / Prius & Perancis & Induksi \\
Renault / & Motor \\
Kangoo & USA & Induksi \\
Chevrolet / & & Motor \\
Silverado & Induksi \\
Daimler & Jerman / & Motor \\
Chrysler / & USA & Induksi \\
Durango & & Motor \\
BMW / X5 & Jerman & Induksi \\
\hline Tesla / Model S & USA &
\end{tabular}

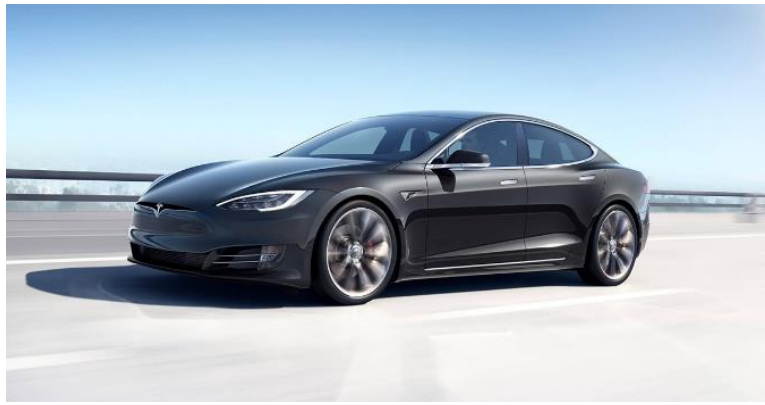

Gambar 1. Mobil listrik Tesla - Model S (https://www.tesla.com/models) 
Tabel 2. Evaluasi Performa Motor Listrik

(Zeraoulia, Benbouzid, \& Diallo, 2006),

(Hashernnia \& Asaei, Comparative Study of

Using Different Electric Motors in the Electric Vehicles, 2008)

\begin{tabular}{lcccc}
\hline \multicolumn{1}{r}{$\begin{array}{r}\text { Jenis Motor } \\
\text { Listrik }\end{array}$} & DC & MI & PMSM & SRM \\
Karakteristik & & & & \\
\hline Power Density & 2.5 & 3.5 & 5.0 & 3.5 \\
Efisiensi & 2.5 & 3.5 & 5.0 & 3.5 \\
Pengendalian & 5.0 & 5.0 & 4.0 & 3.0 \\
Kehandalan & 3.0 & 5.0 & 4.0 & 5.0 \\
Kesiapan & 5.0 & 5.0 & 4.0 & 4.0 \\
Teknologi & 4.0 & 5.0 & 3.0 & 4.0 \\
Biaya & & & & \\
\hline
\end{tabular}

Berdasarkan data evaluasi performa motor listrik pada Tabel 2, motor induksi merupakan kandidat yang sesuai dengan mobil listrik. Motor induksi memiliki tingkat kesiapan teknologi tinggi dengan pengendalian dan kehandalan yang lebih baik dari motor DC, PMSM maupun SRM. Kesiapan teknologi motor induksi didukung oleh beberapa riset mengenai pengaturan vektor dan pengembangan metode pengendali yang digunakan (intelligent control, robust control dan adaptive control) yang semakin berkembang dan menjadi topik utama riset pengembangan konsep kendaraan ramah lingkungan dan hemat energi (K, Ushakumari, \& V., 2012), (Oliveira, Aguiar, Monteiro, \& Pereira, 2015), (Quang \& Dittrich, 2015), (Thomas \& Koshy, 2013). Pada pengaturan vektor, motor induksi dapat diperlakukan seperti motor DC sehingga pengaturan fluks dan torsi motor induksi dapat dilakukan secara terpisah. Pada sisi efisiensi dan power density motor induksi lebih baik dari motor DC dan setara dengan SRM namun tidak lebih baik dari PMSM.

\section{KESIMPULAN}

Publikasi ilmiah ini mengevaluasi penggunaan motor listrik sebagai penggerak utama mobil listrik. Motor listrik yang digunakan terbagi dalam empat jenis, yaitu : motor DC, SRM, PMSM dan motor induksi. Motor DC dikembangkan sebagai penggerak mobil listrik pada generasi awal dikarenakan kemudahan pada pengaturan dan pengendaliannya. Selain itu motor DC memiliki fluks dan torsi yang terpisah. SRM banyak digunakan sebagai penggerak mobil hybrid dikarenakan konstruksi dan toleransi kesalahan saat pengoperasiannya. Motor induksi merupakan jenis motor listrik yang sesuai untuk mobil listrik. Hal ini dikarenakan tingkat kesiapan teknologi, kehandalan dan pengendalian yang tinggi dimiliki oleh motor induksi. Satu - satunya motor listrik yang mampu menyamai penggunaan motor induksi sebagai penggerak mobil listrik adalah PMSM. PMSM memiliki power density yang lebih baik dikarenakan berat keseluruhan dan ukuran yang lebih kecil daripada motor induksi.

\section{UCAPAN TERIMA KASIH}

Ucapan terima kasih ditujukan kepada pihak - pihak yang terlibat dan turut aktif menyelesaikan penelitian ini. Terutama kepada P3M - Politeknik Negeri Balikpapan (P3M - POLTEKBA) yang telah memberikan dukungan finansial dengan nomer kontrak : 23/PL32.13/SPK-LT/2019.

\section{DAFTAR PUSTAKA}

Assegaf, A., Purwadi, A., Rachmilda, T. D., \& Haroen, Y. (2013). Dynamic Response Analysis of Permanent Magnet Brushless DC Motor Drives for City Electric Car Based on Matlab / Simulink. 2013 Joint International Conference on Rural Information \& Communication Technology and Electric-Vehicle Technology (rICT \& ICeV-T). Bandung - Bali.

Bitar, Z., \& Jabi, S. A. (2014). Studying the Performances of Induction Motor Used in Electric Car. The International Conferences on Technologies and Materials for Renewable Energy, Environment and Sustainability. Beirut.

BPPT. (2018). OUTLOOK INDONESIA ENERGY 2018 : Energi Berkelanjutan untuk Transportasi Darat. Jakarta: Pusat Pengkajian Industri dan Proses Energi (PPIPE) - Badan Pengkajian dan Penerapan Teknolog (BPPT).

Eisler, M. N. (2016). A Tesla in Every Garage? IEEE SPECTRUM, 53(2), 34 - 55.

Fard, S. M., Khajepour, A., Goodarzi, A., \& Esmailzadeh, E. (2012). Design and control of a narrow electric vehicle. International Electric Vehicle Conference. Greenville.

Hashernnia, N., \& Asaei, B. (2008). Comparative Study of Using Different Electric Motors in the Electric Vehicles. International Conference on Electrical Machines (pp. 1-5). Vilamoura: IEEE. 
Hashernnia, N., \& Asaei, B. (2008). Comparative Study of Using Different Electric Motors in the Electric Vehicles. International Conference on Electrical Machines. Vilamoura.

Jaya, A., Purwanto, E., Fauziah, M. B., Murdianto, F. D., Prabowo, G., \& Rusli, M. R. (2017). Design of PID-Fuzzy for Speed Control of Brushless DC Motor in Dynamic Electric Vehicle to Improve Steady-State Performance. International Electronics Symposium on Engineering Technology and Applications (IES-ETA) (pp. 179 - 184). Surabaya: IEEE.

K, N. G., Ushakumari, \& V., L. Z. (2012). Harmonic Elimination of Space Vector Modulated Three Phase Inverter. International MultiConference of Engineers and Computer Scientists. Hong Kong.

Kiyota, K., Kakishima, T., Sugimoto, H., \& Chiba, A. (2013). Comparison of the Test Result and 3D-FEM Analysis at the Knee Point of a $60 \mathrm{kWSRM}$ for a HEV. IEEE TRANSACTIONS ON MAGNETICS, 49(5), 2291 - 2294.

Kumar, S., \& D.Susitra. (2016). A SRM Drive Based Hybrid Electric Vehicle with Reduced Switch Converter. International Conference on Green Engineering and Technologies (ICGET). Coimbatore.

Mehazzem, F., Nemmour, A. L., \& Reama, A. (2017). Real time implementation of backstepping-multiscalar control to induction motor fed by voltage source inverter. International Journal of Hydrogen Energy, 42(28), 17965 17975.

Oliveira, C. M., Aguiar, M. L., Monteiro, J. B., \& Pereira, W. C. (2015). Vector Control of Induction Motor using a Sliding Mode Controller with Chattering Reduction. IEEE Brazillian Electronics Conferrence and 1st Southern Power Electronics Conferrence (COBEP/SPEC). Fortaleza.

Quang, N. P., \& Dittrich, J.-A. (2015). Vector Control of Three-Phase AC Machines. Berlin: Springer-Verlag Berlin Heidelberg.

Saleki, A., Rezazade, S., \& Changizian, M. (2017). Analysis and Simulation of Hybrid Electric Vehicles for Sedan Vehicle. Iranian Conference on Electrical Engineering. Tehran.
Sieklucki, G. (2018). An Investigation into the Induction Motor of Tesla Model S Vehicle. International Symposium on Electrical Machines (SME). Andrychów.

Sriwilai, A., Pattaraprakorn, W., Chutiprapat, V., Sansilah, C., \& Bhasaputra, P. (2016). The Study on the Effect of Electric Car to Energy Consumption in Thailand. 13th International Conference on Electrical Engineering/Electronics, Computer, Telecommunications and Information Technology (ECTI-CON). Chiang Mai: IEEE.

Thomas, S., \& Koshy, R. A. (2013). Efficiency Optimization with Improved Transient Performance of Indirect Vector Controlled Induction Motor Drive. International Journal of Advanced Research in Electrical, Electronics and Instrumentation Engineering, 2(1), 374 - 385.

Wang, S., Zhan, Q., Ma, Z., \& Zhou, L. (2005). Implementation of a $50-\mathrm{kW}$ FourPhase Switched Reluctance Motor Drive System for Hybrid Electric Vehicle. IEEE TRANSACTIONS ON MAGNETICS, 41(1), 501 - 504.

Yaich, M., Hachicha, M. R., \& Ghariani, M. (2015). Modeling and Simulation of Electric and Hybrid Vehicles for Recreational Vehicle. International conference on Sciences and Techniques of Automatic control \& computer engineering - STA. Monastir.

Yang, Z., Shang, F., Brown, I. P., \& Krishnamurthy, M. (2015). Comparative Study of Interior Permanent Magnet, Induction and Switched reluctance Motor Drives for EV and HEV Applications. IEEE Transactions on Transportation Electrification, 245 - 254.

Zeraoulia, M., Benbouzid, M. E., \& Diallo, D. (2006). Electric Motor Drive Selection Issues for HEV Propulsion Systems: A Comparative Study. IEEE Transactions on Vehicular Technology, 55(6), 1756 1764 . 